This item was submitted to Loughborough's Research Repository by the author.

Items in Figshare are protected by copyright, with all rights reserved, unless otherwise indicated.

\title{
Cadmium chloride-assisted re-crystallization of CdTe: the effect of annealing over-treatment
}

PLEASE CITE THE PUBLISHED VERSION

http://dx.doi.org/10.1109/PVSC.2014.6925018

PUBLISHER

(C) IEEE

\section{VERSION}

SMUR (Submitted Manuscript Under Review)

\section{PUBLISHER STATEMENT}

This work is made available according to the conditions of the Creative Commons Attribution-NonCommercialNoDerivatives 4.0 International (CC BY-NC-ND 4.0) licence. Full details of this licence are available at: https://creativecommons.org/licenses/by-nc-nd/4.0/.

\section{LICENCE}

CC BY-NC-ND 4.0

\section{REPOSITORY RECORD}

Abbas, Ali, G.D. West, Jake W. Bowers, Piotr M. Kaminski, Bianca Maniscalco, Michael Walls, Kurt L. Barth, and Walajabad S. Sampath. 2019. "Cadmium Chloride-assisted Re-crystallization of Cdte: The Effect of Annealing Over-treatment”. figshare. https://hdl.handle.net/2134/15678. 


\title{
Cadmium Chloride Assisted Re-Crystallization of CdTe: The effect of annealing over-treatment
}

\author{
A. Abbas ${ }^{1,2}$, G.D West ${ }^{2}$, J.W. Bowers ${ }^{1}$, P. M. Kaminski ${ }^{1}$, B. Maniscalco ${ }^{1}$, J.M. Walls ${ }^{1}$, K.L. Barth ${ }^{3}$ and \\ W.S. Sampath ${ }^{3}$ \\ ${ }^{1}$ CREST (Centre for Renewable Energy Systems and Technology), ${ }^{2}$ Department of Materials \\ Loughborough University, Loughborough, United Kingdom \\ ${ }^{3}$ NSF I/UCRC for Next Generation Photovoltaics, Colorado State University, Fort Collins, United States
}

\begin{abstract}
Although the cadmium chloride treatment is an essential process for high efficiency thin film cadmium telluride photovoltaic devices, the precise mechanisms involved that improve the cadmium telluride layer are not fully understood. The treatment parameters have a narrow window, deviating from these even slightly can be detrimental to cell performance. In this investigation we apply advanced microstructural characterization techniques to study the effects of varying two parameters: the temperature of the substrate during the cadmium chloride treatment and the length of time of the treatment. In both cases, the devices have been deliberately overtreated. The effect of the over-treatment on the microstructure of cadmium telluride solar cells, deposited by close spaced sublimation is investigated and related to cell performance. A range of techniques has been used to observe the changes to the microstructure as well as the chemical and crystallographic changes as a function of treatment parameters. Electrical tests that link the device performance with the microstructural properties of the cells have also been undertaken. Techniques used include Transmission Electron Microscopy (TEM) for subgrain analysis, EDX for chemical analysis and XPS for composition-depth profiling.
\end{abstract}

Index Terms - CdTe, thin film photovoltaics, Cadmium Chloride, Close Space Sublimation, TEM

\section{INTRODUCTION}

The cadmium telluride/cadmium sulphide photovoltaic system is an important technology, with demonstrated cell efficiencies reaching over 20\% [1]. Cadmium telluride has a band gap of $1.45 \mathrm{eV}$, ideal for photovoltaic conversion. It also has a high absorption coefficient, so that only a thin layer ( $\sim 2$ $\mu \mathrm{m})$ is required for total absorption. The p-type cadmium telluride and n-type cadmium sulphide can be deposited using a variety of methods, which give different structural and chemical properties. Two techniques which have been studied previously include sputter deposition and close spaced sublimation [2,3]. For both of these deposition methods we have found that the as-deposited films contained a high density of stacking faults, some of which cause low cell efficiency. Once the cells are exposed to the cadmium chloride annealing treatment the majority of stacking defects formed during deposition are removed, and cell performance is found to increase dramatically. Precise tuning of the treatment parameters is needed for the cadmium chloride treatment to optimize the cell efficiency. Deviation from these optimized parameters can cause a reduction in cell performance. The two important variable parameters of the cadmium chloride treatment are the annealing temperature of the sample and the annealing time of the treatment. This study concentrates on the effect of these two parameters and observing why it is so critical not to over-treat the CdTe layer with increased annealing time or temperature. Comparing the microstructural properties between the optimized treated samples and those over-treated provides a direct insight into the mechanisms involved in the reduced cell efficiency.

\section{EXPERIMENTAL}

\section{A. Sample Cell Depositions}

The thin film CdTe cells were deposited in a superstrate configuration using close-spaced sublimation on NSGPilkington TEC10 fluorine doped tin oxide (FTO) coated on 3 $\mathrm{mm}$ soda lime glass. A thin layer of cadmium sulphide was deposited onto the transparent conducting oxide at a thickness of $\sim 150 \mathrm{~nm}$. The cadmium telluride was deposited to a thickness of $2.2 \mu \mathrm{m}$. All the films were deposited in an all in one vacuum process, the substrate was passed though different chambers at $40 \mathrm{mTorr}$, held a few millimeters above graphite boats. The boats were heated to $650^{\circ} \mathrm{C}$ with the different materials, which then sublimed onto the inverted substrate [4].

\section{B. Benchmark Cells}

The treatment was carried out in vacuum following the CdTe layer deposition. Cadmium chloride was sublimated to a thickness of $3 \mu \mathrm{m}$, and then the sample was heated to $400^{\circ} \mathrm{C}$ in a $2 \%$ oxygen atmosphere, causing the cadmium chloride layer to evaporate off, this was followed by a copper doping process by sublimating $\mathrm{CuCl}$ onto the CdTe layer [5]. The efficiency of this cell was measured to be $13 \%$. The circular, small area devices of $\sim 1 \mathrm{~cm}^{2}$ area were then finished by applying a graphite paste back contact. The second cell was deposited using the same conditions but no cadmium chloride treatment was carried out; effectively it was an untreated cell. The efficiency of this cell was measured to be less than $1 \%$. 


\section{Variation of Annealing Time and Temperature}

The benchmark or 'process of reference' conditions for the cadmium chloride treatment uses an annealing temperature of $400^{\circ} \mathrm{C}$ for 2 minutes to yield an efficiency of $13 \%$.

To study the effects of over-treating the cell by varying the anneal temperature; cells were annealed above the optimum temperature to $429^{\circ} \mathrm{C}$. The efficiency of this cell reduced and was measured to be less than $9 \%$. Samples were also treated at an annealing temperature of $411{ }^{\circ} \mathrm{C}$.

The time of the cadmium chloride annealing treatment was also varied from 120 seconds which has been found to be the optimum time. The annealing time was increase from 120 seconds to 600 seconds; this caused a drop in cell efficiency to less than 5\%. A 300 seconds anneal time was also investigated. As the annealing time and temperature was increased, their effects on the cells microstructure and chemical properties were investigated and these observations were correlated to the reduction in cell performance. This provides an insight into the mechanisms by which the cadmium chloride treatment causes changes to the CdTe microstructure and affects cell efficiency.

\section{Characterization}

Transmission Electron Microscopy (TEM) was the tool used to investigate the detailed microstructure of the cells. TEM samples were prepared by Focused Ion Beam (FIB) milling using a dual beam FEI Nova 600 Nanolab. A standard in situ lift out method was used to prepare cross-sectional samples through the coating into the glass substrate. A platinum overlayer was deposited to define the surface of the samples and homogenize the final thinning of the samples. Once the thickness of the samples had been reduced to less than $100 \mathrm{~nm}$ thick, a lower voltage ( $5 \mathrm{kV}$ ) ion beam was used to remove any damage to the sample, including ion implantation and amorphisation. High resolution TEM imaging of CdTe grains was carried out using a FEI Tecnai F20 by tilting to the [011] zone axis. The TEM was also equipped with an Oxford Instruments X-Max 80 silicon drift detector (SDD) Energy Dispersive X-ray detector (EDX), used to produce chemical distribution maps of the cells, as well as line scans and point analysis. To improve spatial resolution of the maps, a smaller condenser aperture was used $(70 \mu \mathrm{m})$ in combination with the largest spot size; these settings provided enough counts without causing excessive beam spreading in the sample. A Thermo Scientific K-Alpha X-ray Photo-electron Spectroscopy (XPS) system was used for composition-depth profiling, using standard relative sensitivity factors to calculate atomic concentrations.

\section{RESULTS}

\section{A. Benchmark Samples}

The two benchmark samples were characterized for comparison: one underwent the previously optimized post deposition annealing cadmium chloride treatment and the other sample was untreated after the CdTe deposition.

The untreated cell, shown in the BF-STEM image in Figure 1 shows the CdTe grain morphology with smaller grains nucleating adjacent to the CdS layer. Some CdTe grains also appear highly faulted; the grains which appear apparently defect free are far off the major zone axis, obscuring the appearance of the defects.

The chemical distribution maps in figure 1 of the untreated CdTe cell shows no diffusion of sulphur into the CdTe layer from the CdS and no tellurium diffusion into the CdS.

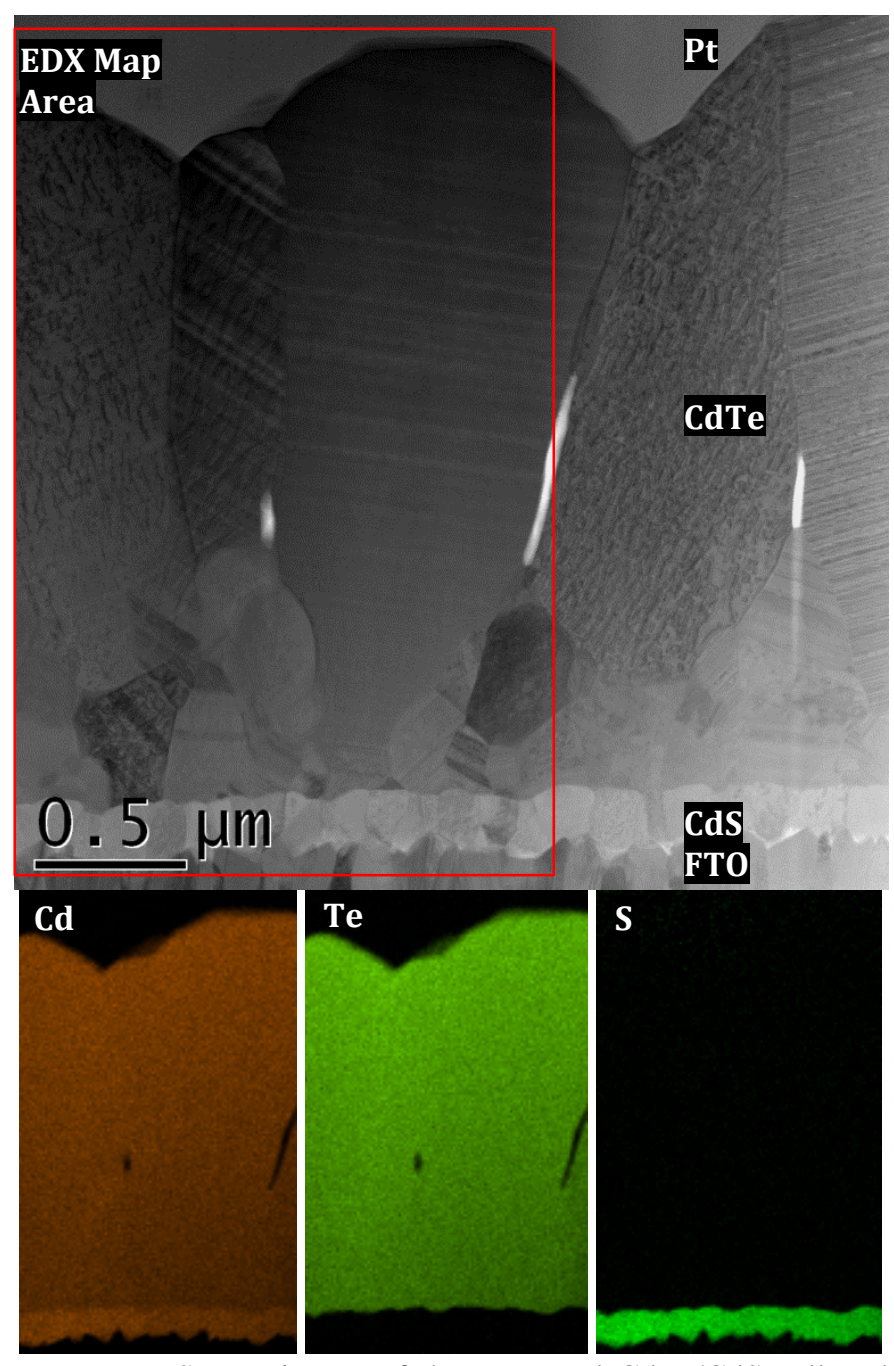

Fig. 1. BF-STEM image of the untreated CdTe/CdS cell and corresponding EDX chemical distribution maps 
Figure 2 shows a high-resolution TEM image of a CdTe grain from an untreated cell showing a high density of planar defects. This is a typical observation for an untreated cell. The defects are a mixture of stacking faults and twin boundaries, whereas the treated cell shown in figure 3 has a perfect lattice. Figure 4 shows the treated cell containing twin boundaries. Some types of stacking faults within the CdTe grains strongly affect the electrostatic potential and behave as hole traps and possess high stacking fault energies of up to $235 \mathrm{~mJ} / \mathrm{m}^{2}$ as determined by Density Functional Theory calculations [6].

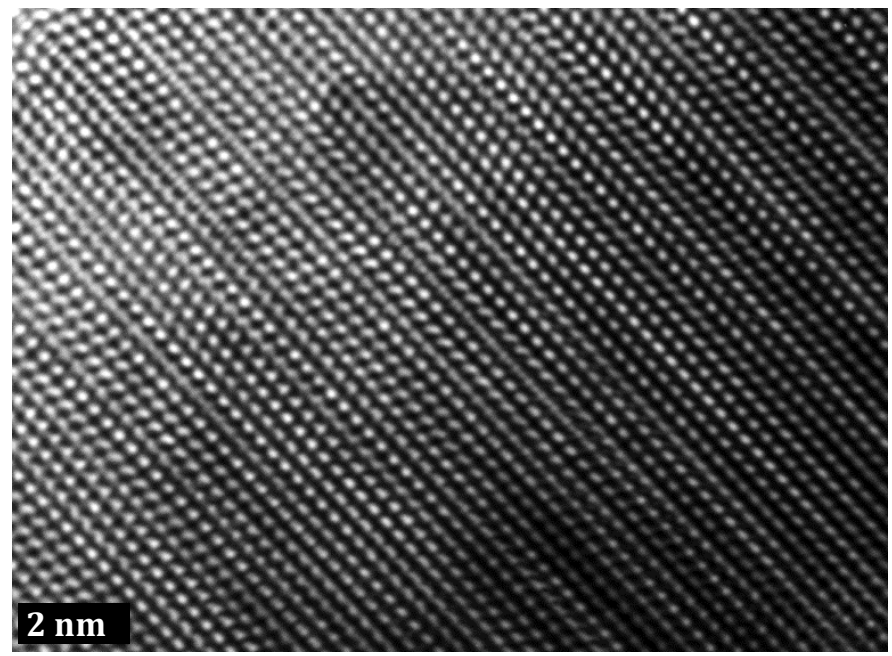

Fig. 2. A high-resolution TEM image of a CdTe grain from an untreated cell showing a high density of extended defects

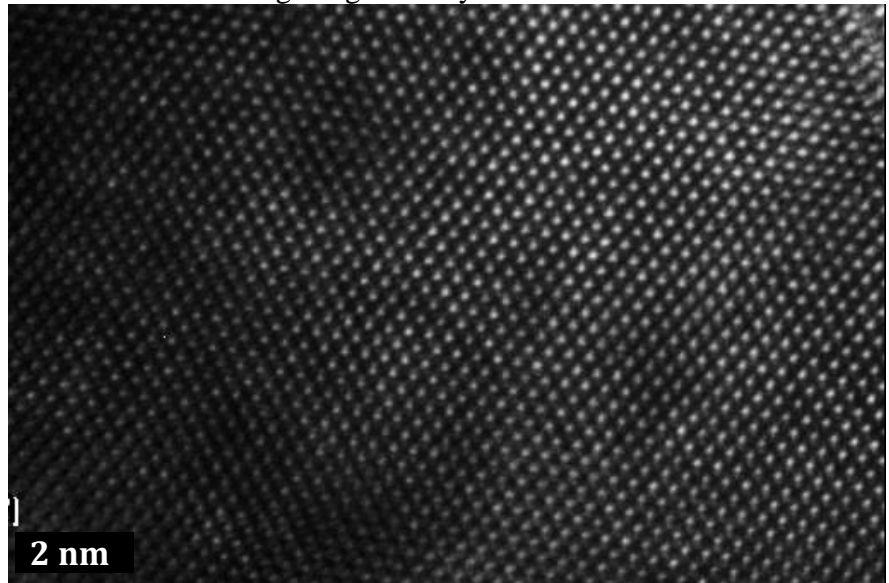

Fig. 3. A high-resolution TEM image of a CdTe grain from a treated cell showing a perfect crystal lattice

Figure 4 shows an image from the device treated for 120 seconds at $400^{\circ} \mathrm{C}$ which is the optimum time and temperature leading to the highest efficiency. The device exhibits a number of twin defects but no stacking faults. The size of the CdTe grains ranges from $\sim 0.5 \mu \mathrm{m}$ to $2 \mu \mathrm{m}$ in diameter. The twin defects in the grains are observed as parallel lines extending from one side of the grain and terminating at the grain boundaries. A change of contrast occurs between the twins due to the change in lattice direction of $60^{\circ}$. There is also a lighter region above the CdS layer which is a chlorine rich area as determined by the EDX maps. The cadmium chemical distribution map shows the highest level of cadmium in the CdS layer, with a lower concentration in the chlorine rich region. No tellurium diffusion into the CdS layer is observed; however sulphur has diffused into the CdTe layer mainly along grain boundaries but has also penetrated into the grains. The chlorine EDX map shows segregation of chlorine at the CdTe grain boundaries but no diffusion into the grains, indicating that the CdTe grains are more porous to sulphur than chlorine. XPS showed a chlorine concentration of 0.3 at $\%$ at the CdS/CdTe interface. The removal of stacking faults from the CdTe grains corresponds directly to the increase in cell efficiency.

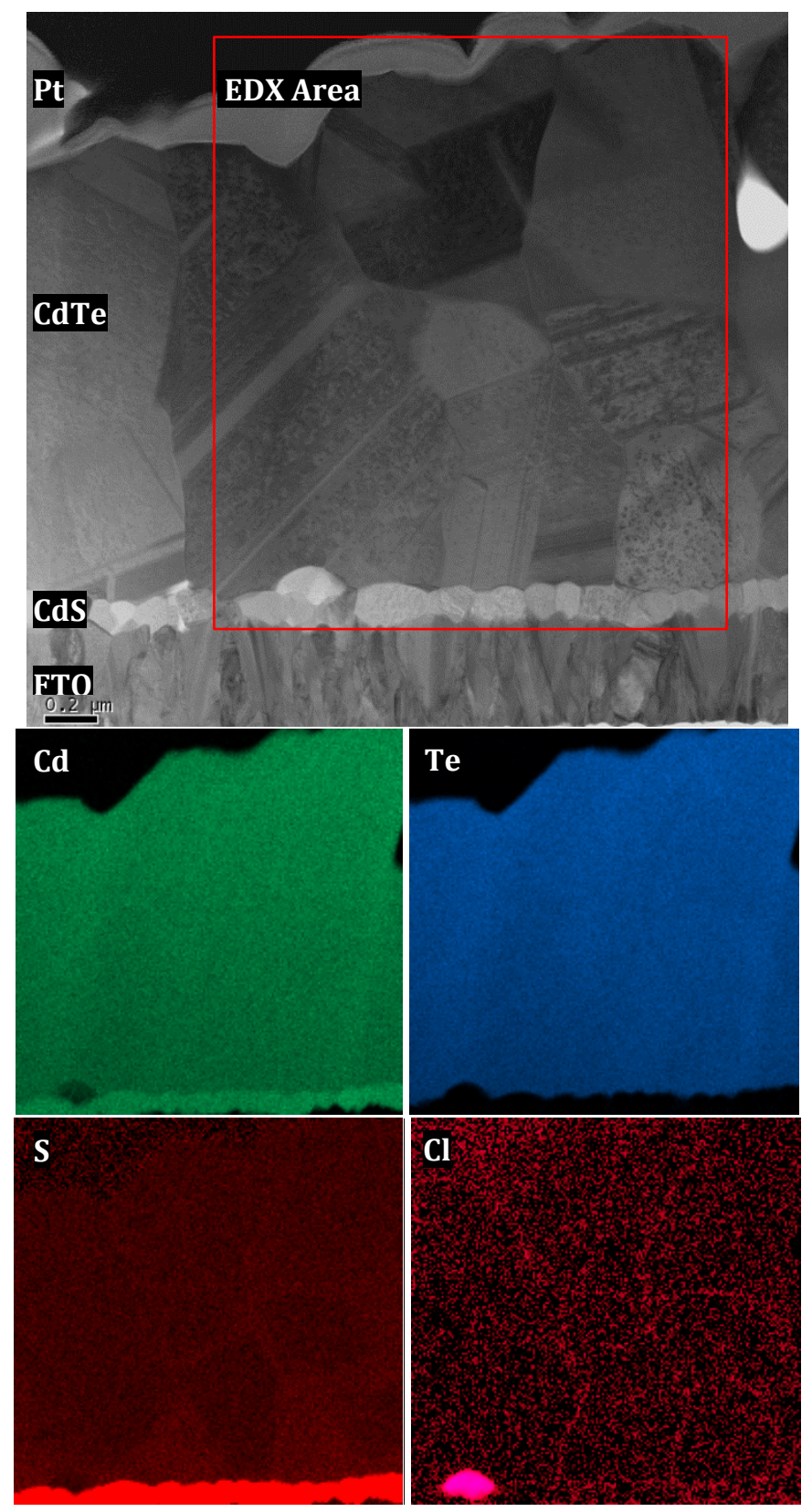

Fig. 4. BF-STEM images of the optimized treated sample with corresponding chemical distribution maps 


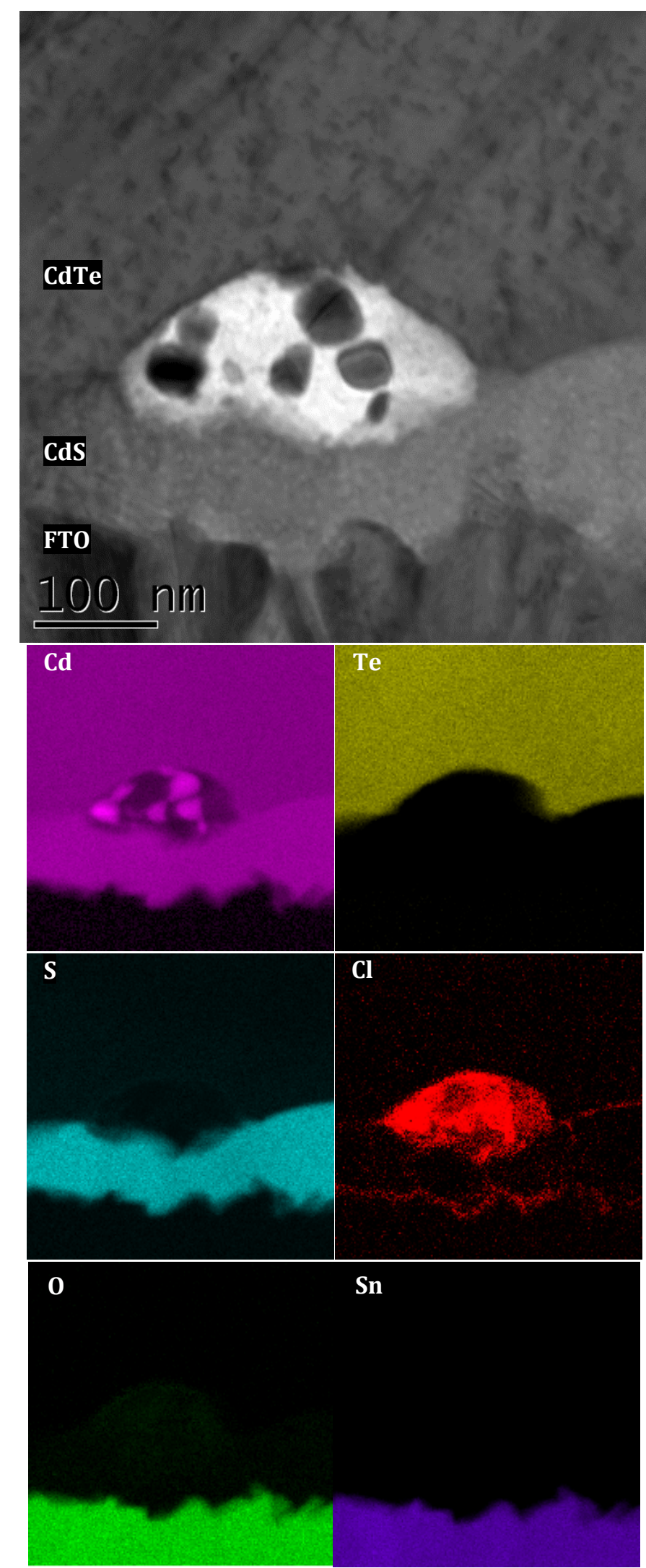

Fig. 5. BF-STEM images of a chlorine rich region in the optimized treated sample with corresponding chemical distribution maps.
Figure 5 shows a higher magnification BF-STEM image of the chlorine rich region observed at the CdTe/CdS interface in Figure 4. The area shows darker precipitates within a lighter region. The region does not sit along a CdTe grain boundary as would be expected; therefore the chlorine has diffused along the CdTe/CdS interface to build up at this point..This is shown in the chlorine chemical distribution map as chlorine has segregated at the $\mathrm{CdTe} / \mathrm{CdS}$ interface to either side of the chlorine rich area. Cadmium and chlorine make up the darker areas in the region. The lighter areas contain less cadmium and more oxygen. Note also the presence of chlorine in the $\mathrm{CdS}$ grain boundaries. Sulphur and tellurium have not diffused into the region.

\section{B. Variation of treatment time and temperatures}

At the optimized annealing time of 120 seconds all stacking faults are removed and only twin defects remain and this corresponds to highest cell efficiency. A further increase in annealing time results in larger grains with a lower density of twin defects. However, this also corresponds to the observation of increased chlorine build up at the CdTe/CdS interface as shown in figure 6 . As the chlorine concentration increases at the interface the efficiency decreases indicating that chlorine build up at the interface is detrimental to the p-n junction. The relationship between chlorine concentration at the junction and cell efficiency is shown in figure 7. In some areas present in the sulphur map, the CdS thin film has almost completely diffused into the CdTe. In one region it has been replaced by a chlorine rich area. The presence of chlorine in the CdS grain boundaries is again observed.

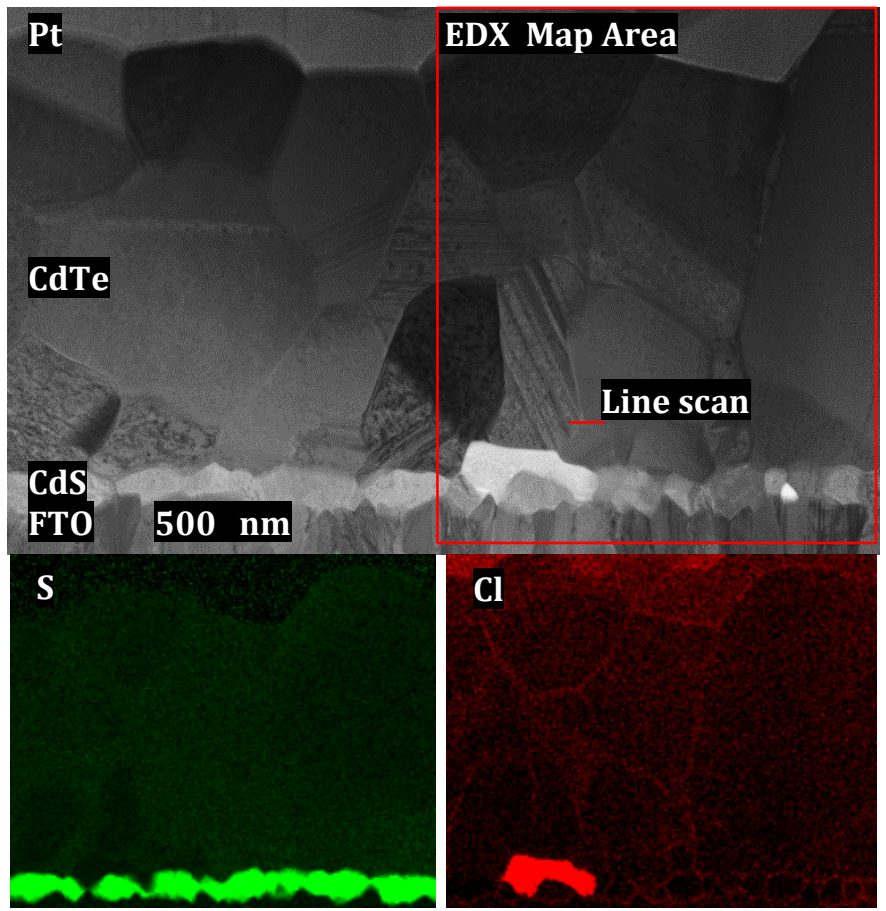

Fig. 6. BF-STEM images of the cell treated for 600 seconds with corresponding chemical distribution maps 


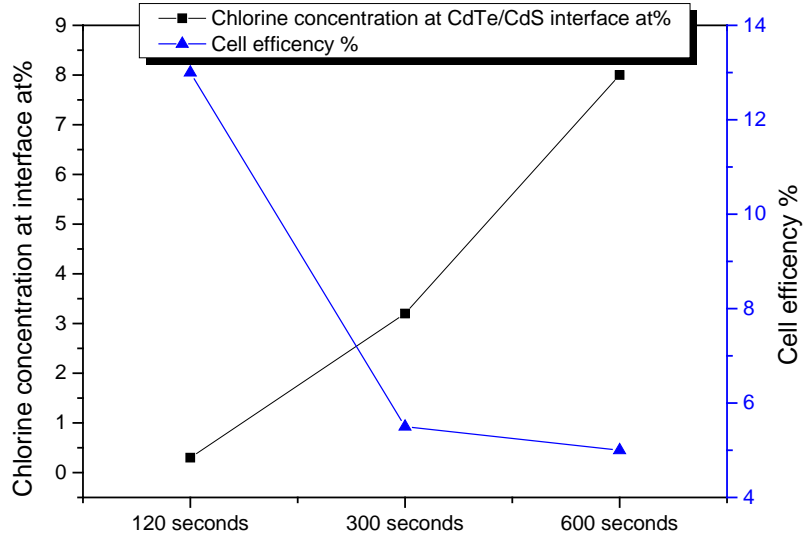

Fig. 7. Chlorine concentration at the CdS/CdTe interface (black line) and cell efficiency varying with annealing treatment time

Figure 8 shows the large chlorine rich region displacing some of the CdS layer observed in Figure 6. In this region two CdTe grain boundaries terminate above the region, which both show chlorine segregation. The sulphur map shows that its diffusion into the CdTe layer is non-homogenous and appears to diffuse into some CdTe grains in preference to others. The cadmium map shows areas of high cadmium concentration in the region.
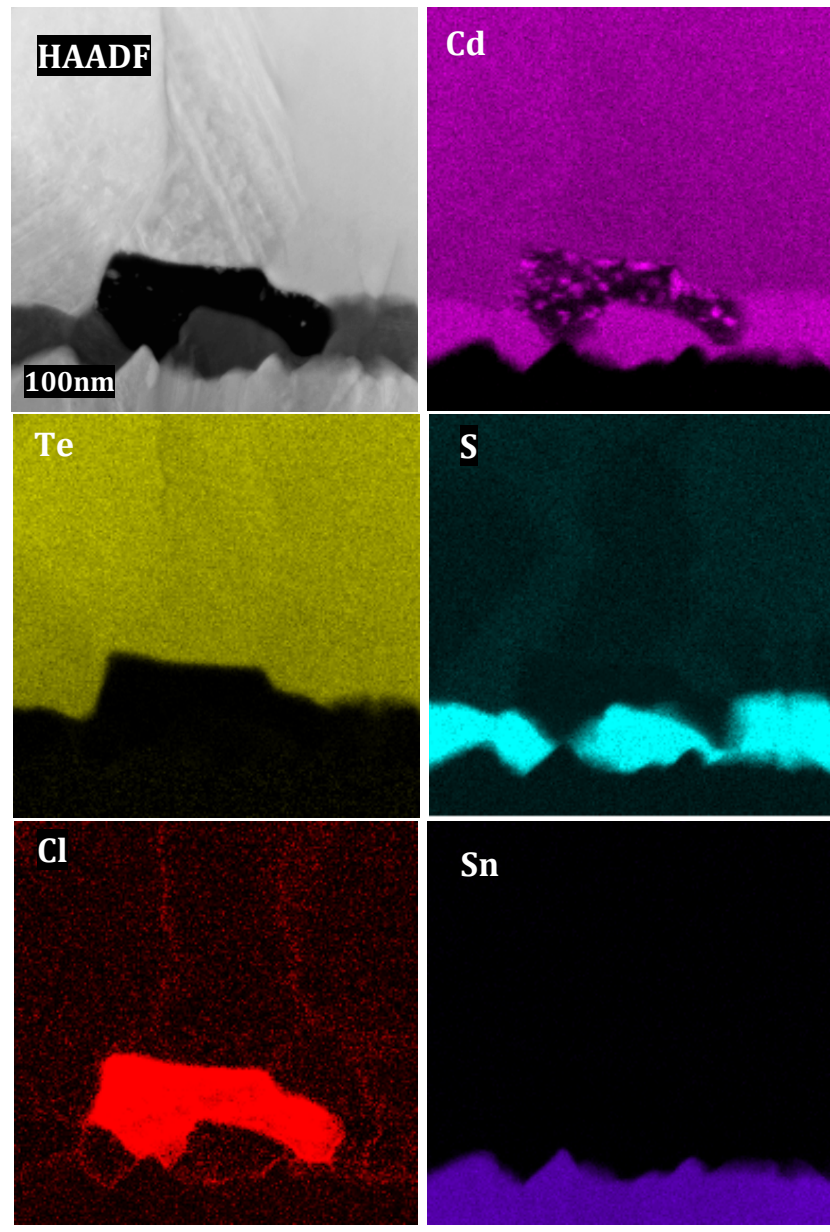

Fig. 8. HAADF-STEM image of the chlorine rich region of the cell treated for 600 seconds with corresponding chemical maps
As figure 8 has shown precipitates of cadmium in the chlorine rich region, some dissociation of $\mathrm{Cd}$ from the $\mathrm{CdCl}_{2}$ is evident. Both figure 6 and figure 8 shows that chlorine is present along all the CdTe and CdS grain boundaries, as well as at the CdTe/CdS and CdS/FTO interfaces. Quantitative EDX measurements from a precipitate within the chlorine rich region showed 70 at\% $\mathrm{Cd}$ and 20 at\% $\mathrm{Cl}$ with 10 at\% O. The less cadmium rich zone showed 40 at\% Cd, 35 at\% $\mathrm{Cl}$ and 25 at\% $\mathrm{O}$.

Figure 9 shows a line scan across a CdTe grain boundary highlighted in Figure 4 in the sample treated for 600 seconds. The chlorine concentration increases at the grain boundary to 1.5 at\%, with little diffusion into the grains either side. This was also observed in the chemical distribution maps. Sulphur concentration increases at the grain boundary to above 1 at $\%$ and levels off at 0.7 at\% in one grain but no sulphur is observed in the adjacent grain. Oxygen is observed at the grain boundary at a concentration of 0.5 at\%.

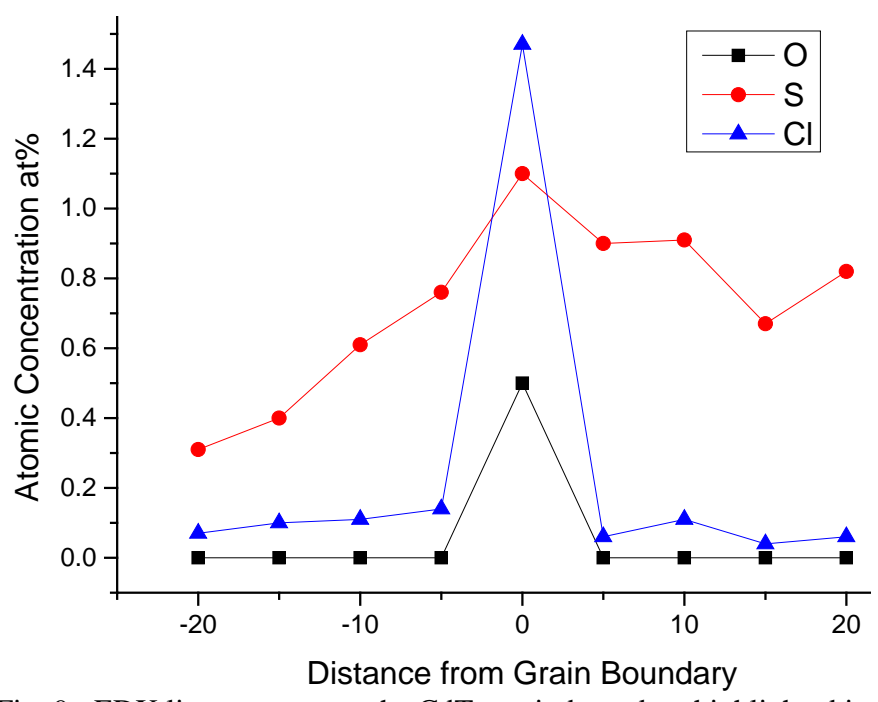

Fig. 9. EDX line scan across the CdTe grain boundary highlighted in Figure 6

The annealing temperature also has a marked effect on the diffusion of chlorine to the CdS interface.as shown in Figure 10. The sample over-treated at $429^{\circ} \mathrm{C}$ results in a high chlorine concentration at the CdS interface. The relationship between annealing temperature, chlorine concentration and cell efficiency is shown in figure 11. Although over-treatment improves the microstructure of the CdTe layer, the increased concentration of chlorine at the CdS interface appears to damage the heterojunction. 


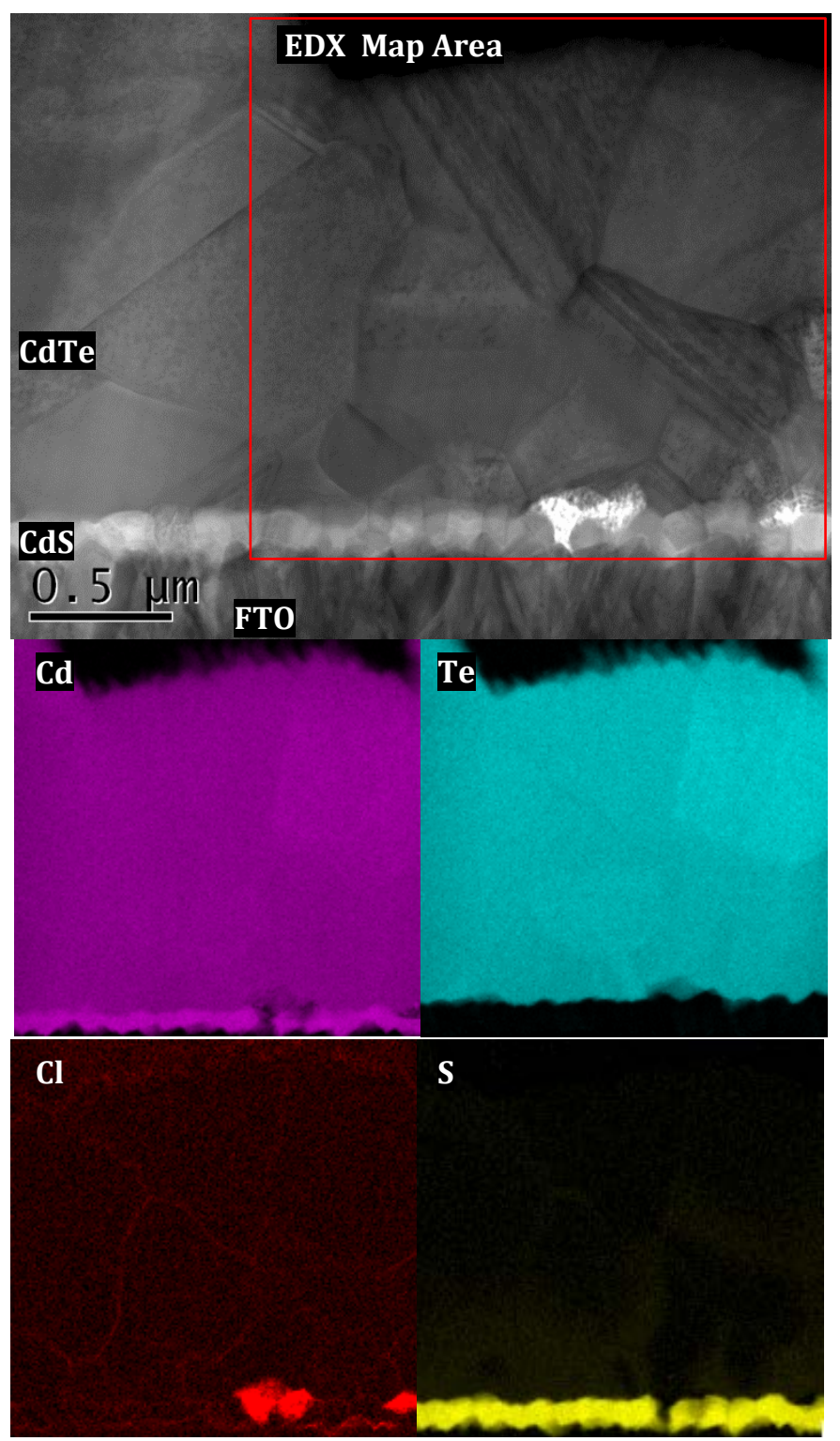

Fig. 10. BF-STEM images of chlorine rich region in the cell treated at $429^{\circ} \mathrm{C}$ with corresponding chemical distribution maps

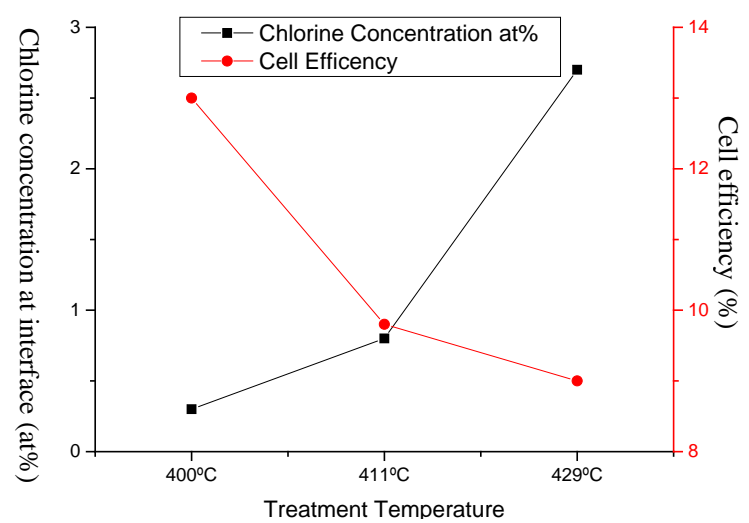

Fig. 11. Chlorine concentration at the CdS/CdTe interface (black line) and cell efficiencies with varying annealing treatment temperature

\section{CONCLUSIONS}

This paper has confirmed the observation that as-deposited thin film CdTe contains high densities of stacking faults some of which act as hole traps. The cadmium chloride treatment completely removes these defects. Twin boundaries are observed to remain in the treated material [3]. The optimal annealing temperature for the cadmium chloride annealing treatment has been found to be $400^{\circ} \mathrm{C}$. The optimum annealing time is 120 seconds. As the annealing temperature is increased a larger average grain size, with more throughthickness grains is observed. However, increasing the temperature of the annealing treatment above $400^{\circ} \mathrm{C}$ results in a high concentration of chlorine at the CdS interface. This has been detected using XPS composition depth profiling. This build-up of chlorine is also directly observable in STEM/EDX which shows chlorine rich regions at the CdTe/CdS interface. Chemical maps have also shown chlorine segregation at grain boundaries, as well as sulphur diffusion into the CdTe grains via the grain boundaries during the treatment. The build-up of chlorine at the interface corresponds to a reduction in cell efficiency indicating that damage is occurring at the heterojunction. A similar pattern is observed as the annealing time is increased. Over-treatment for longer than 120 seconds again results in higher concentrations of chlorine at the $\mathrm{CdTe} / \mathrm{CdS}$ interface. Once again, the increased chlorine buildup corresponds to reduced cell efficiency even though the microstructure of the CdTe layer is improved.

\section{ACKNOWLEDGEMENTS}

The Loughborough authors are grateful to EPSRC for financial assistance through the Supergen SuperSolar Hub and the CSU authors to the NSF I/UCRC and AIR programs

\section{REFERENCES}

[1] First Solar (www.firstsolar.com)

[2] A. Abbas, J.W. Bowers, B. Maniscalco, S. Moh, G.D West, P.N. Rowley, H.M Upadhyaya, J. M. Walls (2011). Characterization of Thin Film photovoltaic materials deposited by high plasma density magnetron sputtering, MRS proceedings, Cambridge University Press, (2011) 1323.

[3] A. Abbas, G.D. West, J.W. Bowers, P. Isherwood, P.M. Kaminski, B. Maniscalco, P. Rowley, J.M. Walls, K. Barricklow, W.S. Sampath, K.L. Barth, "The Effect of Cadmium Chloride Treatment on Close-Spaced Sublimated Cadmium Telluride Thin-Film Solar Cells," , IEEE Journal of Photovoltaics , vol.3, no.4, pp.1361,1366, Oct. 2013 doi:10.1109/JPHOTOV.2013.2264995

[4] Barth, K.L.; Enzenroth, R.A.; Sampath, W.S "Advances in continuous, in-line processing of stable CdS/CdTe devices," Photovoltaic Specialists Conference, 2002. Conference Record of the Twenty-Ninth IEEE, pp. 551- 554, 19-24 May 2002

[5] Barth, K. L., R. A. Enzenroth, and W. S. Sampath, "Apparatus and Processes for the Mass Production of Photovoltaic Modules" US patent 6,423,565, July 23, 2002.

[6] S.H. Yoo, K.T. Butler, A. Soon, A. Abbas, J.M. Walls, A. Walsh, Identification of critical stacking faults in thin-film CdTe solar cells, submitted to Applied Physics Letters 